\title{
FAKTOR PENGHAMBAT PEMBERIAN ASI EKSKLUSIF PADA IBU BEKERJA DI KOTA BLORA
}

\author{
Yanik Muyassaroh ${ }^{1)}$ Rizky Amelia ${ }^{1)}$ Komariyah $^{1)}$ \\ E-mail address: yanikmuyass@gmail.com
}

\begin{abstract}
Breastfeeding is one of the first steps for a human being to get a healthy and prosperous life. Data from the Blora District Health Office, the number of infants aged 624 months was 1,063 babies. Of these figures, exclusive breastfeeding rates are still around $75 \%$. The exclusive breastfeeding coverage is still below the target in accordance with the Republic of Indonesia Law No. 25 of 2000 concerning the National Development Program (Propenas) in 2000-2004, which states the level of achieving exclusive breastfeeding by 80\%. The 2012 Indonesian Demographic Health Survey (IDHS) shows that $57 \%$ of the workforce in Indonesia are women. In Blora City, there are already ASI corner facilities in various fields of work, facilities and different policies, but still not supporting the mastery of ASI. Data from the Blora District Health Office, the number of infants aged 6-24 months was 1,063 babies. This research is a quantitative observational analytic study, a cross-sectional approach with a population of 72 people. Samples were taken by Total Sampling. The analysis used is Chi-Square analysis and Logistics regression. The results showed there was a positive and statistically significant effect between policies $(\mathrm{OR}=0.043$; CI 95\% 0.005-0.375; $\mathrm{p}=0.004)$, working hours $(\mathrm{OR}=0.049 ; \mathrm{CI} 95 \% 0.003-0.733 ; \mathrm{p}=0.029)$, availability of places pumping breast milk $(\mathrm{OR}=0.034$; CI 95\% 0.004-0.290; $\mathrm{p}=0.002)$ and leadership support with exclusive breastfeeding (OR $=0.057$; CI 95\% 0.006-0.526; $\mathrm{p}=0.012)$. It is recommended that the Health Service and Puskemas can work together with companies / factories / places of work to improve facilities and infrastructure that can support working mothers in breastfeeding.

Keywords: Exclusive Breastfeeding; Working mother

1) Poltekkes Kemenkes Semarang
\end{abstract}

\section{Pendahuluan}

Menyusui merupakan salah satu langkah pertama bagi seorang manusia untuk mendapatkan kehidupan yang sehat dan sejahtera. Hal tersebut tercantum di dalam Sustainable Development Goals (SDGs) atau tujuan pembangunan berkelanjutan tahun 2030.Tetapi, di beberapa negara maju dan berkembang termasuk Indonesia banyak ibu karir yang tidak menyusui secara eksklusif.Data dari Survey Demografi Kesehatan Indonesia
(SDKI) 2012 menunjukkan bahwa pemberian ASI eksklusif di Indonesia adalah $42 \%$.

Menyusui merupakan hak setiap ibu, termasuk ibu bekerja. Dalam Konvensi Organisasi Pekerja Internasional tercantum bahwa cuti melahirkan selama 14 minggu dan penyediaan sarana pendukung ibu menyusui di tempat kerja wajib diadakan. Undang-Undang Perburuhan di Indonesia No.1 tahun 1951 memberikan cuti melahirkan selama 12 minggu dan kesempatan menyusui $2 \mathrm{x}$ 
30 menit dalam jam kerja. Namun ibu bekerja masih dianggap sebagai salah satu faktor penyebab tingginya angka kegagalan menyusui, padahal di negara-negara industri $45-60 \%$ tenaga kerja merupakan wanita usia produktif.

Selain itu Pemberian ASI eksklusif juga telah diatur dalam Peraturan Bersama Menteri Negara Pemberdayaan Perempuan, Menteri Tenaga Kerja dan Transmigrasi, dan Menteri Kesehatan No. 48/MEN.PP/XII/2008,PER.27/MEN/X II/2008, dan 1177/MENKES/PB/XII/2008 Tahun 2008 tentang Peningkatan Pemberian Air Susu Ibu Selama Waktu Kerja di Tempat Kerja. Dalam Peraturan Bersama tersebut antara lain disebutkan bahwa Peningkatan Pemberian ASI selama waktu kerja di tempat kerja adalah program nasional untuk tercapainya pemberian ASI eksklusif 6 (enam) bulan dan dilanjutkan pemberian ASI sampai anak berumur 2 (dua) tahun). Berdasarkan Peraturan Bersama tersebut, Menteri Tenaga Kerja dan Transmigrasi bertugas dan bertanggung jawab mendorong pengusaha/pengurus serikat pekerja/serikat buruh agar mengatur tata cara pelaksanaan pemberian ASI dalam Peraturan Perusahaan atau Perjanjian Kerja Bersama dengan mengacu pada ketentuan Peraturan Perundang-undangan Ketenagakerjaan.

Survey Demografi Kesehatan Indonesia (SDKI) 2012 menunjukkan bahwa57\% tenaga kerja di Indonesia adalah wanita.Faktor-faktor yang menghambat keberhasilan menyusui pada ibu bekerja adalah pendeknya waktu cuti kerja, kurangnya dukungan tempat kerja, pendeknya waktu istirahat saat bekerja (tidak cukup waktu untuk memerah ASI), tidak adanya ruangan untuk memerah ASI, pertentangan keinginan ibu antara mempertahankan prestasi kerja dan produksi ASI.

Persoalan hak ibu bekerja untuk menyusui anaknya menjadi sangat penting jika dilihat dari jumlah ibu pekerja di Indonesia. Hak ibu sebagai tenaga kerja telah diatur dalam Undang - Undang No.13 tahun 2003 tentang ketenagakerjaan, yaitu : memperoleh cuti istirahat selama 1,5 bulan sebelum dan 1,5 bulan sesudah melahirkan (Pasal 82) dan pekerja/buruh perempuan yang anaknya masih menyusu harus diberi kesempatan untuk menyusui anaknya jika harus dilakukan selama waktu kerja (pasal 83) (Nurjanah,2008).

Kembali bekerja setelah cuti melahirkan merupakan kendala suksesnya PP-ASI.Chatterji dan Frick (2005) menyatakan bahwa kembali bekerja dalam tiga bulan pertama setelah melahirkan sangat berhubungan dengan penurunan untuk memulai menyusui sebesar 16-18\%, dan pengurangan durasi menyusui sekitar 4-5 minggu. Weber et al (2011) menyatakan bahwa kembali bekerja adalah alasan utama unuk berhenti menyusi, dari $60 \%$ wanita yang berniat terus menyusui namun hanya $40 \%$ yang melakukannya.

Di Purwokerto Jawa Tengah, dalam penelitian karyawan di Perguruan Tinggi Negeri menunjukkan presentase pemberian ASI eksklusif hanya mencapai $21 \%$, sebagian besar kegagalan disebabkan oleh sikap ibu terhadap pemberian ASI eksklusif dan peraturan di tempat kerja (Rahardjo \& Dyah, 2009).

World Health Organization (WHO), American Academy of 
Pediatrics (AAP), American Academy of Family Physicians (AAFP) dan Ikatan dokter Anak Indonesia (IDAI) merekomendasikan pemberian ASI eksklusif selama 6 bulan dan pemberian ASI dapat dilanjutkan sampai 2 tahun. Telah dibuktikan bahwa ibu menyusui memberikan berbagai keuntungan bukan hanya bagi bayi dan ibu saja namun juga bagi tempat kerja sang ibu. Angka absensi ibu pada perusahaan lebih rendah karena anak lebih jarang sakit. Dengan memberikan ASI kedekatan ibu dengan bayi tetap dipertahankan, bahkan pada saat berjauhan, serta menghemat pendapatan ibu karena tidak perlu membeli susu formula.

Beberapa hasil penelitian yang pernah dilakukan menunjukan bahwa ibu bekerja adalah salah satu faktor penyebab gagalnya pemberian ASI eksklusif. Saleh (2011), menemukan bahwa pemberian susu formula menjadi satu satunya alternatif dalam pemberian makanan bagi bayi yang ditinggalkan di rumah oleh ibu yang bekerja. Mulyaningsih (2010) menemukan bahwa dari 100 ibu yang bekerja, hanya 11 orang ibu yang memberikan ASI eksklusif.Selain itu Hikmawati (2008) juga menemukan bahwa faktor ibu bekerja penyebab kegagalan pemberian ASI selama dua bulan.

Menurut (Haryono dan Setianingsih, 2014) rendahnya presentase pemberian Air Susu Ibu (ASI) eksklusif karena banyaknya faktor diantaranya adalah ibu yang bekerja.Dari hasil penelitian (Oktora, 2013) menyatakan bahwa ibu bekerja yang memberikan ASI eksklusif hanya 4 responden dari 18 responden.Sisanya tidak memberikan ASI eksklusif. Hal ini dapat dikarenakan beberapa faktor. Salah satu faktor yaitu tidak adanya kebijakan di perusahaan terkait pemberian ASI, dukungan pimpinan, jam kerja yang tidak sesuai, dan ketersediaan tempat untuk memerah ASI. Faktor-faktor tersebut dapat menghambat peningkatan prosentase pemberian ASI eksklusif secara menyeluruh.

Pemerintah Indonesia sebenarnya sudah memberikan dukungan bagi para ibu pekerja agar tetap dapat memberikan ASI pada bayinya dalam PP No.33 Tahun 2012 pasal 30 mengatur tentang penyediaan fasilitas khusus untuk menyusui dan/atau memerah ASI. Pengurus tempat kerja dan penyelenggara tempat sarana umum wajib menyediakan fasilitas khusus ini sesuai dengan kemampuan perusahaan/institusi.Tetapi dalam pelaksanaannya belum semua perusahaan melaksanakan peraturan tersebut.

Selain itu, jam kerja juga mempengaruhi keberhasilan pemberian ASI termasuk di dalamnya adalah jenis pekerjaan dan lamanya kerja. Ibu yang bekerja di administrasi atau kantor memiliki kesempatan untuk menyusui bayinya lebih lama dibandingkan dengan ibu yang bekerja secara profesional. Ibu yang bekerja paruh waktu juga memiliki kemungkinan memberikan waktu menyusui lebih lama dibandingkan ibu yang bekerja full-time (Novayelinda, 2012).

Untuk mencapai keberhasilan ibu dalam menyusui eksklusif, perlu adanya dukungan dari berbagai pihak.Salah satunya adalah dukungan pimpinan dimana ibu bekerja.Hasil penelitian Amin, et al (2011) bahwa 
tempat kerja yang tidak mempunyai fasilitas menyusui yang tidak adekuat merupakan factor risiko terjadinya kegagalan menyusui pada ibu bekerja.Pojok laktasi sangat penting keberadaannya untuk suksesnya pemberian ASI.Di Kota Blora sendiri untuk fasilitas pojok ASI dengan bernagai macam bidang pekerjaan, fasilitas dan kebijakan yang berbeda, sudah ada yang mendukung program ASI eksklusif dan masih banyak juga yang belum.Data dari Dinas Kesehatan Kabupaten Blora, jumlah bayi usia 6-24 bulan adalah 1.063 bayi. Dari angka tersebut angka menyusui secara eksklusif masih dikisaran 75\%. Cakupan ASI eksklusif tersebut masih dibawah target yang sesuai dengan UU RI No 25 Tahun 2000 tentang Program Pembangunan Nasional (Propenas) tahun 2000-2004, yang mencantumkan tingkat pencapaian pemberian ASI eksklusif sebesar 80\%. Di Kabupaten Blora sendiri dari studi pendahuluan yang telah dilakukan banyak sekali ibu bekerja yang tidak menyusui secara eksklusif karena berbagai macam alasan.Masih rendahnya persentasi pemberian ASI eksklusif tersebut merupakan salah satu permasalahan kesehatan reproduksi yang menarik untuk di kaji. Oleh sebab itu, peneliti tertarik untuk melihat lebih dalam lagi mengenai faktor apa saja yang menghambat pemberian ASI eksklusif pada ibu bekerja.

Tujuan penelitian ini adalah untuk mengkaji lebih dalam tentang faktor - faktor yang mempengaruhi pemberian ASI eksklusif pada ibu bekerja.

\section{Metode Penelitian}

Penelitian ini merupakan penelitian kuantitatif dengan jenis observasional analitik, pendekatan cross-sectional (potong-lintang). Dengan pendekatan potong-lintang, artinya semua variabel yang diteliti diukur pada saat yang sama.

Populasi dalam penelitian ini adalah semua ibu menyusui yang bekerja di kota Blora. Sedangkan populasi sasaran dalam penelitian ini adalah ibu menyusui yang bekerja di di kota Blora.

Teknik sampling yang digunakan untuk mendapatkan sampel adalah total sampling yaitu dengan mengambil semua sampel yang ada dengan jumlah 72 orang, dengan kriteria inklusi :

1. Ibu yang mau menjadi responden

2. Ibu bekerja yang mempunyai bayi usia 6 - 24 bulan

Data yang dikumpulkan adalah data primer dan data sekunder. Data primer diperoleh melalui angket yang diberikan kepada responden. Sedangkan data sekunder diperoleh dari Kantor/ tempat bekerja responden.Sebelum pengambilan data didahului dengan informed consent dan menganut azas kerahasiaan.

Instrument yang digunakan adalah angket yang berisi tentang umur, pendidikan dan jenis persalinan, pemberian ASI, frekuensi Pemberian ASI eksklusif, kebijakan, jam kerja, ketersediaan tempat memompa ASI, dan dukungan pimpinan.

Uji normalitas data menggunakan Uji Kolmogorov Smirnov. Analisa data yang digunakan adalah dengan menggunakan analisis Chi Square dan Regresi Logistik. 


\section{Hasil dan Pembahasan}

Tabel 1.Distribusi data karakteristik berdasarkan umur.

\begin{tabular}{ccc}
\hline Umur & Frekuensi & Prosentase \\
\hline $\begin{array}{c}<20 \\
\text { tahun }\end{array}$ & 2 & $2.7 \%$ \\
$\begin{array}{c}20-35 \\
\text { tahun } \\
>35\end{array}$ & 68 & $94.6 \%$ \\
tahun & 2 & $2.7 \%$ \\
\hline Total & 72 & $100 \%$ \\
\hline
\end{tabular}

Berdasarkan Tabel 1 dapat diketahui bahwa sebagian responden berusia reproduktif, yaitu $94.6 \%$ responden berusia 20-35 tahun.

Tabel 2.Distribusi data karakteristik berdasarkan pendidikan.

\begin{tabular}{ccc}
\hline Pendidikan & Frekuensi & Prosentase \\
\hline SD & 3 & $4.2 \%$ \\
SMP & 56 & $77.8 \%$ \\
SMA & 13 & $18 \%$ \\
\hline Total & 72 & $100 \%$ \\
\hline
\end{tabular}

Berdasarkan tabel 2 dapat diketahui bahwa sebagian besar responden berpendidikan SMP yaitu sebesar $77.8 \%$.

Tabel 3.Distribusi data karakteristik berdasarkan jenis Persalinan.

\begin{tabular}{ccc}
\hline Jenis & Frekuensi & Prosentase \\
\hline Spontan & 68 & $94.4 \%$ \\
SC & 4 & $5.6 \%$ \\
\hline Total & 72 & $100 \%$ \\
\hline
\end{tabular}

Berdasarkan tabel 3 dapat diketahui bahwa sebagian besar responden melahirkan secara spontan yaitu $94.4 \%$.
Tabel 4. Distribusi data berdasarkan Distribusi frekuensi Pemberian ASI eksklusif, kebijakan, jam kerja, ketersediaan tempat memompa ASI, dan dukungan pimpinan.

\begin{tabular}{|c|c|c|}
\hline Variabel & $\mathrm{N}$ & Prosentase \\
\hline \multicolumn{3}{|l|}{ Kebijakan } \\
\hline - Ada & 28 & $38.9 \%$ \\
\hline - Tidak ada & 44 & $61.1 \%$ \\
\hline Total & 72 & $100 \%$ \\
\hline \multicolumn{3}{|l|}{ Jam kerja } \\
\hline - $7-8$ jam & 16 & $22.2 \%$ \\
\hline - $\quad>8 \mathrm{jam}$ & 56 & $77.8 \%$ \\
\hline Total & 72 & $100 \%$ \\
\hline \multirow{2}{*}{\multicolumn{3}{|c|}{$\begin{array}{l}\text { Ketersediaan tempat } \\
\text { menyusui/memerah } \\
\text { ASI }\end{array}$}} \\
\hline & & \\
\hline - Ada & 23 & $31.9 \%$ \\
\hline - Tidak ada & 49 & $68.1 \%$ \\
\hline Total & 72 & $100 \%$ \\
\hline \multicolumn{3}{|l|}{ Dukungan pimpinan } \\
\hline - Mendukung & 34 & $47.2 \%$ \\
\hline $\begin{array}{l}\text { - Tidak } \\
\text { mendukung }\end{array}$ & 38 & $52.8 \%$ \\
\hline Total & 72 & $100 \%$ \\
\hline \multicolumn{3}{|l|}{ Pemberian ASI } \\
\hline \multicolumn{3}{|l|}{ Eksklusif } \\
\hline - $\mathrm{Ya}$ & 23 & $31.9 \%$ \\
\hline - Tidak & 49 & $68.1 \%$ \\
\hline Total & 72 & $100 \%$ \\
\hline
\end{tabular}

Berdasarkan Tabel 4 dapat diketahui bahwa pada sebagian besar tempat bekerja subjek penelitian tidak ada kebijakan tentang pemberian ASI eksklusif pada jam kerja yaitu sebesar $61.1 \%$. Sebagian besar subjek penelitian memiliki jam kerja lebih dari 8 jam kerja karena mengambil jam lembur yaitu sebesar 77.8\%. Pada tempat bekerja subjek penelitian sebagian besar tidak memiliki tempat untuk menyusui atau memerah ASI yaitu sebesar 68.1\%.Pimpinan dari 
perusahaan tempat bekerja subjek penelitian sebagian besar tidak mendukung pemberian ASI eksklusif bagi karyawan yang masih memberikan ASI pada bayinya yaitu sebesar $52.8 \%$. Pada subjek penelitian sebagian besar tidak memberikan ASI eksklusif $(68,1 \%)$.

Tabel 5. Pengaruh kebijakan tentang asi eksklusif terhadap pemberian ASI Ekslusif pada ibu bekerja di Kota Blora

\begin{tabular}{lllllll}
\hline kebijakan & \multicolumn{2}{c}{ ASI } & \multicolumn{3}{c}{ Total } \\
& Eks & \multicolumn{2}{c}{ Tidak } & \multicolumn{2}{c}{} \\
& $\mathrm{n}$ & $\%$ & $\mathrm{n}$ & $\%$ & $\mathrm{n}$ & $\%$ \\
\hline Ada & 18 & 78 & 10 & 20.4 & 28 & 38.9 \\
Tidak & 5 & 21. & 39 & 79.6 & 44 & 61.1 \\
& & 7 & & & & \\
Total & 23 & 100 & 49 & 100 & 72 & 100 \\
\hline OR & 14,04 & \multicolumn{5}{c}{$\mathrm{p}$} \\
\hline \multicolumn{5}{c}{ Tabel } & 5 & \multicolumn{3}{c}{ menunjukkan } & nilai
\end{tabular}

Odds Ratio sebesar 14,04 berarti ibu yang di tempat kerjanya ada kebijakan tentang pemberian ASI eksklusif kemungkinan 14,04 kali lebih besar memberikan ASI secara eksklusif dibandingkan ibu yang di tempat kerjanya tidak ada kebijakan mengenai pemberian ASI eksklusif. Hasil uji ChiSquare menunjukkan ada hubungan positif antara kebijakan dengan pemberian ASI eksklusif dan secara statistik signifikan $(\mathrm{p}=0,000)$.

Tabel 6.Pengaruh Jam kerja terhadap pemberian ASI Eksklusif pada ibu bekerja di Kota Blora.

\begin{tabular}{|c|c|c|c|c|c|c|}
\hline \multirow{3}{*}{$\begin{array}{l}\text { Jam } \\
\text { kerja }\end{array}$} & \multicolumn{4}{|c|}{ Pemberian ASI Eksklusif } & \multirow{2}{*}{\multicolumn{2}{|c|}{ Total }} \\
\hline & Ya & & Tidak & & & \\
\hline & $\mathrm{n}$ & $\%$ & $\mathrm{n}$ & $\%$ & $\mathrm{n}$ & $\%$ \\
\hline $\begin{array}{l}\text { 7-8 } \\
\text { jam }\end{array}$ & 13 & 56 & 3 & 6.1 & 16 & 22.2 \\
\hline $\begin{array}{l}>8 \\
\text { jam }\end{array}$ & 10 & 43 & 46 & 93.9 & 56 & 77.8 \\
\hline total & 23 & 100 & 49 & 100 & 72 & 100 \\
\hline & OR & & 19,93 & $\mathrm{p}$ & & 0,0000 \\
\hline
\end{tabular}

Odds Ratio sebesar 19,93 berarti ibu yang memiliki jam kerja 7-8 jam sehari kemungkinan 19,93 kali lebih besar memberikan ASI secara eksklusif dibandingkan ibu yang bekerja lebih dari 8 jam sehari. Hasil uji Chi-Square menunjukkan ada hubungan positif antara jam kerja dengan pemberian ASI eksklusif dan secara statistik signifikan $(\mathrm{p}=0,000)$.

Tabel 7. Pengaruh Ketersediaan Tempat Untuk Memompa ASI Bagi Karyawan Menyusui terhadap pemberian ASI Ekslusif pada ibu bekerja di Kota Blora

\begin{tabular}{|c|c|c|c|c|c|c|}
\hline \multirow[t]{2}{*}{$\begin{array}{l}\text { Tempat } \\
\text { pompa } \\
\text { ASI }\end{array}$} & \multicolumn{2}{|c|}{$\begin{array}{l}\text { Pemberian } \\
\text { Eksklusif } \\
\text { Ya }\end{array}$} & \multicolumn{2}{|c|}{ Tidak } & \multicolumn{2}{|c|}{ Total } \\
\hline & $\mathrm{n}$ & $\%$ & $\mathrm{n}$ & $\%$ & $\mathrm{n}$ & $\%$ \\
\hline Tersedia & 17 & 73.9 & 6 & 12.2 & 23 & 31.9 \\
\hline $\begin{array}{l}\text { Tidak } \\
\text { tersedia }\end{array}$ & 6 & 26.1 & 43 & 87.8 & 49 & 68.1 \\
\hline total & 23 & 100 & 49 & 100 & 72 & 100 \\
\hline & OR & 20,30 & & $\mathrm{p}$ & & 0,000 \\
\hline
\end{tabular}

Pada Tabel 7 menunjukkan nilai Odds Ratio sebesar 20,30 berarti ibu yang di tempat kerjanya tersedia tempat untuk menyusui atau memerah ASI kemungkinan 20,30 kali lebih besar memberikan ASI secara eksklusif dibandingkan ibu yang di tempat kerjanya tidak ada tempat untuk menyusui atau memerah ASI. Hasil uji Chi-Square menunjukkan ada hubungan positif antara ketersediaan tempat untuk memompa ASI dengan pemberian ASI eksklusif dan secara statistik signifikan $(p=0,000)$. 
Tabel 8. Pengaruh dukungan pimpinan perusahaan terhadap pemberian ASI Ekslusif pada ibu bekerja di Kota Blora

\begin{tabular}{lcclccc}
\hline Dukun & \multicolumn{2}{l}{ Pemberian } & \multicolumn{3}{c}{ ASI } & \multicolumn{2}{l}{ Total } \\
gan & \multicolumn{2}{l}{ Eksklusif } & \multicolumn{2}{l}{ Tidak } \\
pimpin & Ya & \multicolumn{3}{l}{ Tidak } \\
an & n & $\%$ & n & $\%$ & n & $\%$ \\
\hline Ya & 18 & 78.3 & 16 & 32.6 & 34 & 47.2 \\
Tidak & 5 & 21.7 & 33 & 67.4 & 38 & 52.8 \\
Jumlah & 23 & 100 & 49 & 100 & 72 & 100 \\
\hline & OR & 7,42 & & p & & 0,000 \\
\hline
\end{tabular}

Pada Tabel 8 menunjukkan nilai Odds Ratio sebesar 7.42 berarti ibu yang mendapat dukungan pimpinan untuk pemberian ASI eksklusif kemungkinan 7,42 kali lebih besar memberikan ASI secara eksklusif dibandingkan ibu yang mempunyai pimpinan yang tidak mendukung mengenai pemberian ASI eksklusif. Hasil uji Chi-Square menunjukkan ada hubungan positif antara dukungan pimpinan dengan pemberian ASI eksklusif dan secara statistik signifikan $(\mathrm{p}=0,000)$.

Tabel 9. Analisis regresi logisticganda Determinan faktor yang menghambat pemberian ASI eksklusif pada ibu bekerja

\begin{tabular}{lcccc}
\hline Variabel & \multicolumn{3}{c}{ CI 95\% } & $\mathrm{p}$ \\
& OR & Low & Up & \\
\hline Dukungan & .057 & .006 & .526 & .012 \\
Kebijakan & .043 & .005 & .375 & .004 \\
Jam Kerja & .049 & .003 & .733 & .029 \\
Tempat & .034 & .004 & .290 & .002 \\
pompa & & & & \\
N observasi & 72 & & & \\
- & 30.0 & & & \\
2loglikedkeho & 01 & & & \\
od & & & & \\
\hline Nagelkerke & 79.3 & & & \\
$\mathrm{R}^{2}$ & $\%$ & &
\end{tabular}

Nilai Odds Ratio variabel dukungan pimpinan sebesar 0.057 berarti bahwa ibu yang mendapat dukungan dari pimpinan0.057 kali lebih besar kemungkinan memberikan ASI secara eksklusif daripada ibu yang tidak mendapatkan dukungan dari pimpinan. Hasil penelitian menunjukkan ada hubungan positif antara dukungan pimpinan dengan pemberian ASI eksklusif dan secara statistik signifikan $(\mathrm{OR}=0.057$, $\mathrm{CI}=95 \% ; 0.006$ hingga $0.526 ; \mathrm{p}=$ 0.012).

Dari hasil uji statistik dapat diketahui bahwa ada hubungan positif dan secara statistik signifikan antara dukungan pimpinan dengan pemberian ASI eksklusif $(p=0,012)$. Hal ini sesuai dengan penelitian Irni dan Sutrisminah (2015), bahwadukungan pimpinan untuk menyusui di tempat kerja dapat meningkatkan perilaku ibu bekerja dalam memberikan ASI eksklusif.

Keberhasilan menyusui di tempat kerja sangat dipengaruhi oleh lingkungan kerja yang diciptakan oleh perusahaan.Pimpinan harus memberikan motivasikepada ibu bekerja untuk menghadiri kelas-kelas prenatal menyusui dankelompokkelompok pendukung ASI.Kelas pilihan bagi kedua orang tua (ayahdan ibu) bisa juga ditawarkan oleh pimpinan saat istirahat makan siang dandibimbing oleh seorang perawat/bidan kerja lokal untuk mendidik keluargatentang pilihan makanan bayi dan dukungan yang mereka terima saat di tempatkerja (Setyawati dan Sutrisminah, 2012).

Persepsi pimpinan akan berbeda dengan persepsi ibu bekerja terhadap pemberian ASI eksklusif di tempat bekerja. Pimpinan perusahaan/institusi yang mempunyai pengalaman atau pengetahuan tentang ASI eksklusif 
akan mempertimbangkan kebutuhan dan harapan ibu bekerja di perusahaannya. Kebutuhan dan harapan pimpinan terhadap produktivitas dan kualitas ibu bekerja sangat besar karena mempengaruhi hasil dan biaya produksi yang harusdikeluarkan oleh perusahaan.Informasi tentang manfaat menyusui ASI secara eksklusif sangat penting diketahui oleh pimpinan perusahaan (Glenn, 2008).

Witters-Green

(2003)

menyatakan bahwa sebagian besar pimpinan perusahaan masih belum mengetahui tentang hal ini, bahkan pimpinan perusahaan berpikir bahwa pemberian susu formula merupakan makanan terbaik bagi bayi. Sebagian besar pimpinan tidak memperhatikan manfaat pemberian ASI eksklusif saat bekerja, seperti mengurangi karyawan tidak masuk bekerja karena bayi jarang atau bahkan tidak pernah sakit dan masih sedikit pimpinan perusahaan yangmembuat aturan tentang menyusui di tempat kerja bagi ibu bekerja.

Nilai Odds Ratio variabel kebijakan tempat bekerja sebesar 0.043 berarti bahwa ibu yang di tempat kerjanya ada kebijakan tentang ASI eksklusif, kemungkinan 0.043 kali lebih besar memberikan ASI eksklusif daripada ibu yang di tempat kerjanya tidak ada kebijakan tentang pemberian ASI eksklusif. Hasil penelitian menunjukkan ada hubungan positif antara kebijakan tentang pemberian ASI eksklusif dengan pemberian ASI eksklusif dan secara statistik signifikan $(\mathrm{OR}=0.043, \mathrm{CI}=95 \% ; 0.005$ hingga $0.375 ; \mathrm{p}=0.004)$.

Hasil penelitian ini sejalan dengan penelitian yang dilakukan oleh Kurniawan, Jayanti, dan Astuti (2012), yang menyatakan bahwa belum adanya kebijakan tertulis yang mendukung pekerja wanita dalam pemberian ASI eksklusif mempunyai pengaruh terhadap pemberian ASI eksklusif pada ibu yang bekerja.

Pentingnya kebijakan tertulis yang mendukung pekerja wanita dalam pemberian ASI eksklusif adalah untuk memperkuat dasar hukum pekerja dalam mengimplementasikan ASI eksklusif di tempat kerja, sehingga nantinya akan dapat meningkatkan motivasi dari pekerja untuk tetap memberikan makanan terbaik untuk bayi mereka yaitu ASI (Kurniawan, Jayanti, dan Astuti, 2012).

Kebijakan pemberian Air Susu Ibu eksklusif bagi ibu bekerja adalah pelaksanaan kebijakan bagi pekerja perempuan meliputi pemberian kesempatan atau waktu kepada pekerja perempuan untuk menyusui/memerah ASI selama waktu kerja, Adanya kebijakan tertulis instansi yang mendukung pemberian ASI eksklusif di tempat kerja akan meningkatkan kemungkinan keberhasilan para pekerja untuk memberikan ASI kepada bayinya secara eksklusif. Hal ini berkaitan dengan salah satu dari sepuluh langkah keberhasilan dalam menyusui yaitu adanya kebijakan tertulis tentang menyusui (Melissa, Jati, dan Suparwati, 2015).

Menurut Undang-undang No.13/2003 tentang Ketenagakerjaan menetapkan bahwa, pekerja atau buruh perempuan yang anaknya masih menyusui harus diberi kesempatan sepatutnya untuk menyusui anaknya jika hal itu harus dilakukan selama bekerja.Setiap perusahaan seharusnya mempunyai kebijakan tertulis tentang menyusui.Hal ini dikarenakan pemberian ASI eksklusif tidak sepenuhnya dapat dipenuhi khususnya oleh ibu bekerja.Tidak dapat dipungkiri 
bahwa wanita bekerja ternyata banyak kehilangan dan kekurangan waktu untuk menyusui anaknya, dan juga masih kurangnya komitmen dari penyelenggara tempat kerja yaitu lingkungan perusahaan untuk mengimplementasikan peraturan pendukung pemberian ASI eksklusif.

Oleh karena itu diperlukan kebijakan yang dibuat oleh pengelola perusahaan atau atasannya dalam memberikan air susu ibu secara ekslusif. Karena ASI ekslusif merupakan nutrisi penting untuk pertumbuhan otak dan perkembangan generasi penerus bangsa.(Mellisa, 2016).

Nilai Odds Ratio variabel jam kerja sebesar 0.049 berarti bahwa ibu yang memiliki jam kerja 7-8 jam dalam sehari, kemungkinan 0.049 kali lebih besar memberikan ASI eksklusif kepada bayinya daripada ibu yang bekerja lebih dari 8 jam dalam sehari. Hasil penelitian menunjukkan ada hubungan positif antara jam kerja dengan pemberianASI eksklusif dan secara statistik signifikan $(\mathrm{OR}=0.049$, $\mathrm{CI}=95 \% ; 0.003$ hingga $0.733 ; \mathrm{p}=.029)$.

Dari hasil uji statistik dapat diketahui bahwa ada hubungan positif dan secara statistik signifikan antara jam kerja dengan pemberian ASI eksklusif $(\mathrm{p}=0,029)$.

Berdasarkan hasil penelitian Arifin dalam Mulyaningsih (2010), ibu yang mempunyai jam kerja lebih dari 8 jam sehari mempunyai waktu yang relatif lebih sedikit sedikit untuk rumah tangga, sehingga bisa menyebabkan bayi tidak dapat memperoleh ASI dengan baik dan teratur yang menyebabkan fungsi pengasuhan beralih kepada anggota keluarga yang tinggal dirumah, pada saat itulah umumnya bayi mendapat makanan dan minuman selain ASI.

Ibu dengan jumlah jam kerja kurang dari 40 jam seminggu, rata-rata cenderung untuk menyusui bayi mereka lebih dari enam bulan. Bila lebih dari itu, pemberian ASI eksklusif dinilai bisa menjadi lebih sebentar atau kurang dari 6 bulan.Para peneliti tersebut menganalisis data dari 2.300 ibu yang bekerja sebelum bayi mereka lahir. Pada saat bayi berusia enam bulan, sekitar 60 persen ibu yang bekerja dengan jumlah jam kerja tidak lebih dari 40 jam seminggu, masih menyusui bayi mereka secara eksklusif selama setidaknya 6 bulan.Tetapi, saat jam kerja meningkat lebih dari 40 jam seminggu, kemungkinan untuk terus menyusui menjadi lebih kecil.Hanya 47 persen ibu dengan jam kerja 20-40 jam seminggu yang masih menyusui bayinya hingga 6 bulan, dan hanya 39 persen ibu dengan jam kerja lebih dari 40 jam seminggu yang masih menyusui.Hal tersebut dikarenakan menyusui adalah sebuah kegiatan yang memerlukan banyak waktu, wanita yang bekerja perlu bekerja ekstra untuk bisa memberikan ASI. (Xiang et al, 2016).

$\begin{array}{rrr}\text { Nilai } & \text { Odds Ratio variabe } \\ \text { ketersediaan } & \text { tempat } & \text { untuk }\end{array}$ menyusui/memerah ASI sebesar 0.034 berarti bahwa ibu yang di tempat kerjanya tersedia ruangan untuk memompa ASI atau menyusui, kemungkinan 0.034 kali lebih besar memberikan ASI secara eksklusif daripada ibu yang di tempat kerjanya tidak tersedia tempat untuk memerah ASI. Hasil penelitian menunjukkan ada hubungan positif antara ketersediaan tempat memerah ASI dengan pemberian ASI eksklusif dan secara statistik signifikan $\quad(\mathrm{OR}=0.034$, 
$\mathrm{CI}=95 \% ; 0.04$ hingga $0.290 ; \mathrm{p}=$ $0.002)$.

Dari hasil uji statistik dapat diketahui bahwa ada hubungan positif dan secara statistik signifikan antara ketersediaan tempat untuk memompa ASI dengan pemberian ASI eksklusif $(\mathrm{p}=0,002)$.

Hal ini sejalan dengan penelitian Sutrisno dan Utami (2015), yang menyatakan bahwa terdapat pengaruh yang signifikan yaitu sebesar 4 kali antara ketersediaan ruang menyusui terhadap pemberian ASI eksklusif pada ibu bekerja di Sleman Yogyakarta.

Ketersediaan tempat memompa ASI adalah tersedianya ruangan ketika ibu menyusui atau memerah ASI ditempat kerja yang memiliki syaratsyarat tertentu dan merasa nyaman menggunakan ruangan tersebut. Dukungan fasilitas menyusui akan berdampak positif terhadap pemberian ASI eksklusif pada ibu menyusui yang bekerja. Hal ini dibuktikan dengan penelitian Abdullah (2012) bahwa 64 $\%$ ibu yang mempunyai akses ruang menyusui ditempat kerja memiliki kesempatan memberikan ASI eksklusif lebih besar dari ibu yang tidak memiliki akses ruang menyusui di tempat kerja. Hasil penelitian ini juga sejalan dengan penelitian Amin, et al (2011) bahwa tempat kerja yang tidak mempunyai fasilitas menyusui dan yang tidak adekuat merupakan faktor risiko terjadinya kegagalan menyusui pada ibu bekerja.

Menurut PP No 33 Pasal 32 Tahun 2012 Tentang ASI Eksklusif menyatakan bahwa tempat bekerja harus menyediakan ruang laktasi untuk pegawainya yang menyusui anaknya (Rahadian, 2017). Pusat laktasi perlu diadakan di tempat kerja, ruang yang dibutuhkan tidak perlu mewah, hanya sebuah ruang pribadi yang dilengkapi pintu yang bisa dikunci, wastafel bersih, lemari es untuk menyimpan ASI, kursi yang nyaman, tirai untuk melindungi privasi ibu saat menyusui atau memerah ASI dan persediaan pompa ASI (Setyawati dan Sutrisminah, 2012).

Diketahui bahwa nilai -2 Log likelihood 30.001. Hal ini menunjukkan bahwa ada kesesuaian model dengan data empiris yang dikumpulkan.

Nilai Nagelkerke's R square 79.3 yang artinya dalam model regresi logistik ini, variable kebijakan tempat bekerja, jam kerja, dukungan pimpinan, dan ketersediaan tempat untuk memerah ASI (pojok ASI) secara bersama hanya mampu menjelaskan $79.3 \%$ dari semua variabel dalam pemebrian ASI eksklusif, sisanya $20.7 \%$, dijelaskan variabilitas dari variabel lain diluar model.

\section{Simpulan}

Rata-rata (mean) intensitas nyeri kesimpulan dari penelitian ini adalah sebagai berikut :

1. Ada pengaruh positif dan secara statistik signifikan antara kebijakan dengan pemberian ASI eksklusif $(\mathrm{OR}=0.043$; CI 95\% 0.005-0.375; $\mathrm{p}=0.004)$.

2. Ada pengaruh positif dan secara statistik signifikan antara jam kerja dengan pemberian ASI eksklusif $(\mathrm{OR}=0.049$; CI 95\% 0.003-0.733; $\mathrm{p}=0.029$ ).

3. Ada pengaruh positif dan secara statistik signifikan antara ketersediaan tempat memompa ASI dengan pemberian ASI eksklusif $(\mathrm{OR}=0.034$; CI 95\% 0.004-0.290; $\mathrm{p}=0.002)$. 
4. Ada pengaruh positif dan secara statistik signifikan antara dukungan pimpinan dengan pemberian ASI eksklusif $(\mathrm{OR}=0.057$; CI $95 \%$ 0.006-0.526; $\mathrm{p}=0.012$ ).

Rekomendasi yang dapat diberikan bagi ibu bekerja adalah untuk tetap memberikan ASI Eksklusif kepada bayi nya walaupun tetap melaksanakan tugas sebagai pekerja, bagi Dinas Kesehatan dapat menjalin kerjasama dengan tempat bekerja seperti perusahaan/pabrik/kantor untuk menyediakan sarana dan prasarana yang mendukung pemberian ASI eksklusif pada ibu bekerja, bagi tempat bekerja dapat meningkatkan sarana dan prasarana yang menunjang ibu bekerja dalam pemberian ASI eksklusif serta bagi peneliti selanjutnya dapat meneliti faktor lain yang mungkin berpengaruh terhadap pemberian ASI eksklusif pada ibu bekerja.

\section{Ucapan Terimakasih}

Terimakasih disampaikan kepada Keluarga tercinta yang tak pernah berhenti memberikan doa dan dukungan baik moril maupun materiil. Seluruh Civitas akademika yang selalu memberikan semangat satu sama lain dalam penyusunan naskah publikasi ini.

\section{Daftar Pustaka}

Arno J, Broermann D, Gleason E, Ward AM.Changes to support breastfeeding in the workplace. Amerika: NAEYC; 2010

Chatterji, P dan Frick, K.D.2005. Does Returning to Work After Childbirth Affect Breastfeeding
Practices?Review of Economic of The Household

Glenn JS. 2008.Knowledge, perceptions, and attitudes of managers, coworkers, and employed breastfeeding mothers. AAOHN journal

Green, L.W. Kreuter, M.W, 2010. Health Promotion Planning an Educationa and Environmental Approch; Second Edition, Mayfield Publishing Company. Houston.

Kurniawan, B; Jayanti, S; Astuti, DY. 2012.Analisis Implementasi ASI Eksklusif Pada Ibu Bekerja di PT. X Semarang.Prosiding Seminar NasionalWorld Fit For Children

Melissa, A; Jati, SP; Suparwati, A.2015.Analisis Implementasi Kebijakan Pemberian Air Susu IbuEksklusif Bagi Pekerja di PT. Apac Inti Corpora KabupatenSemarang. Jurnal kesehatan masyarakat (ejournal) volume 3 , nomor 2 , april 2015 (issn: 2356-3346)

Novayelinda, R. 2014. Pemberian ASI dan Ibu Bekerja.Jurnal Ners Indonesia

Peraturan Pemerintah RI no 33 tahun 2012 Tentang Pemberian ASI

Eksklusif.

Rahadian, AS.2014. Pemenuhan Hak ASI Eksklusif di Kalangan Ibu Bekerja: Peluang Dan Tantangan (fulfilling the right for exclusive breastfeeding among working women: opportunities and challenges).Pusat Penelitian Kependudukan Lembaga Ilmu Pengetahuan Indonesia 
Roesli, U, 2009. Mengenal ASI Eksklusif. Jakarta : PT. Pustaka Pembangunan Swadaya Nusantara.

Saleh, LA. 2011. Faktor-faktor yang menghambat praktik ASI Eksklusif pada Bayi 0-6 bulan.

Setyawati, I; Sutrisminah, E.2012. Pentingnya Motivasi Dan Persepsi Pimpinan TerhadapPerilaku Pemberian Asi Eksklusif Pada Ibu Bekerja

Sutrisno, A.H; dan Utami, S.F. 2015.Ketersediaan Ruang Menyusui Terhadap ASI Eksklusif Pada Ibu Bekerja di Sleman Yogyakarta. Jurnal STIKES Aisyiyah Yogyakarta

Weber, D; Janson, A; Nolan, M; Wen, LM; \& Risel C.2011.Female Employees perceptions of Organisational Support For Breastfeeding AtWork: Findings From an Australian Health Service Workplace. International Breastfeeding Journal

Widia, C.2014.Faktor-faktor eksternal yang berhubungan dengan kegagalan pemberian asi ekslusif oleh ibu yang bekerja.Jurnal kesehatan bakti tunas husada volume 11 no. 1 februari 2014

Xiang, N; Zadoroznyj, M;

Tomaszewski, W; Martin,B.2016. Timing of

Return to Work and Breastfeeding in Australia. PEDIATRICS (ISSN Numbers: Print, 0031-4005; Online, 1098 4275). 